\title{
A Web-Based Gamification Program to Improve Nutrition Literacy in Families of 3- to 5-Year-0ld Children: The Nutriscience Project
}

\author{
José Azevedo, $\mathrm{PhD}^{1,2}$; Patrícia Padrão, $\mathrm{PhD}^{2,3}$; Maria J. Gregório, $\mathrm{PhD}^{3,4}$; \\ Carla Almeida, $\mathrm{BSc}^{3}$; Nuno Moutinho, $\mathrm{PhD}^{5}$; Nanna Lien, $\mathrm{PhD}^{6}$; Renata Barros, $\mathrm{PhD}^{2,3}$
}

\begin{abstract}
Objective: Assess the impact of a web-based gamification program on nutrition literacy of families and explore differences in impact by socioeconomic status.

Design: Quasi-experimental.

Setting: Thirty-seven kindergartens from Portugal.

Participants: Eight hundred seventy-seven families.

Intervention: Web-based social network of participants' interactions, educational materials, apps and nutritional challenges, focused on fruit, vegetables, sugar, and salt.

Main Outcome Measures: Parental nutrition literacy (self-reported survey -4 dimensions: Nutrients, Food portions, Portuguese food wheel groups, Food labeling).

Analysis: General linear model - Repeated measures was used to analyze the effect on the nutrition literacy score.

Results: Families uploaded 1267 items (recipes, photographs of challenges) and educators uploaded 327 items (photographs, videos) onto the interactive platform. For the intervention group ( $\mathrm{n}=106)$, the final mean (SD) score of nutrition literacy was significantly higher than the baseline: $78.8 \%(15.6)$ vs $72.7 \%$ (16.2); $P<.001$, regardless of parental education and perceived income status. No significant differences in the scores of the control group $(n=83)$ were observed (final 67.8\% [16.1] vs initial 66.4\% [15.6]; $P=.364$ ). Conclusions and Implications: Gamified digital interactive platform seems to be a useful, easily adapted educational tool for the healthy eating learning process. Future implementations of the program will benefit from longer time intervention and assessment of the eating habits of families before and after intervention.

Key Words: nutrition literacy, families, kindergarten children, gamification (J Nutr Educ Behav. 2019; 51:326-334.)
\end{abstract}

Accepted October 13, 2018. Published online December 20, 2018.

\section{INTRODUCTION}

Noncommunicable diseases (NCD) are the main cause of mortality worldwide, responsible for two thirds of all deaths in 2015. ${ }^{1}$ Unhealthy diet is considered one the most important lifestyle risk factors for NCD and is associated with frequent metabolic/ physiologic changes such as high blood pressure, high fasting blood glucose, high blood lipids, and

\footnotetext{
${ }^{1}$ Faculdade de Letras, Universidade do Porto, Porto, Portugal

${ }^{2}$ EPIUnit - Instituto de Saúde Pública, Universidade do Porto, Porto, Portugal

${ }^{3}$ Faculdade de Ciências da Nutrição e Alimentação, Universidade do Porto, Porto, Portugal

${ }^{4}$ EpiDoC Unit, Centro de Estudos de Doenças Crónicas (CEDOC) da NOVA Medical School, Universidade Nova de Lisboa, Lisboa, Portugal

${ }^{5}$ Faculdade de Economia and Center for Economics and Finance, Universidade do Porto, Porto, Portugal

${ }^{6}$ Department of Nutrition, University of Oslo, Oslo, Norway

Conflict of Interest Disclosure: The authors have not stated any conflicts of interest.

Address for correspondence: José Azevedo, PhD, Faculty of Arts and Humanities, University of Porto Via Panorâmica, s/n Porto 4150-564, Portugal; E-mail: azevedo@letras.up.pt

(C) 2018 Society for Nutrition Education and Behavior. Published by Elsevier Inc. All rights reserved.
}

https://doi.org/10.1016/j.jneb.2018.10.008 overweight/obesity. ${ }^{2}$ Social inequalities persist regarding the distribution of risk factors for NCD, putting the disadvantaged social classes at higher risk. In Portugal, according to a recent national food and physical activity survey, $25 \%$ of children (under 10 years of age) are overweight. ${ }^{3}$ Moreover, unhealthy dietary patterns seem to be the leading cause of the total number of years of healthy life lost (19\%) in the Portuguese population. ${ }^{4}$ In addition, inequalities in energy-balancerelated behaviors in children are well documented, reflected by a higher prevalence of obesity among children whose parents have a low education level. $^{3}$

Evidence shows a strong correlation between nutritional knowledge and healthy eating. ${ }^{5}$ In fact, understanding the importance of nutrition 
seems to be a determinant for prevention and management of different global health concerns. However, while nutrition knowledge is an important enabling factor, it might not be enough to change behavior. In recent years, the ecological model has thus been used to explain and develop interventions to change eating behaviors. ${ }^{6}$ Ecological models are based on the premise that an individual's behavior is shaped by a dynamic interaction with the social and physical environment, which includes influences at the interpersonal, organizational, and community levels and employs a variety of disciplines and perspectives to understand and address complex public health problems. ${ }^{7,8}$ However, the application of the social ecological model has had limited success in changing dietary behaviors. $^{9}$

The combination of traditional ecological systemic approaches with the acknowledgment that in modern life, health and well-being strongly depend on the individual's health behaviors opened new horizons to use motivation as the core concept of a new generation of health communication interventions. This raises the immediate question; what kind of interventions are best positioned to intrinsically motivate health behavior change?

\section{Gamification a New Model?}

A main rationale for using gamification designs in health is that they are systems purpose-built for motivation. Systematic literature review shows that, compared to traditional persuasive approaches, gamification offers several advantages for motivating behavior change for health and well-being. ${ }^{10,11}$ Gamification strategies have already gained recognition for fostering desirable health-related behaviors through motivational reinforcement, personalized teaching approaches, and social networking. ${ }^{12}$ Gamification is a concept that makes use of social mechanisms such as social influence or interaction by applying game mechanics (action points, feedback, competition). ${ }^{13}$ Various studies indicate that specific messages based on group behavior could have the power to influence health-related intentions, ${ }^{14}$ and that individuals use information about how others behave as a guide to appropriate behavior in a given context, especially in uncertain situations. ${ }^{15}$

In short, the main reasons to consider gamification as relevant to health behavior change include:

Intrinsic motivation. The ability to intrinsically motivate the initiation and continued performance of health and well-being behaviors, ${ }^{11,16-19}$ and the well-established advantages of intrinsic over extrinsic motivation with regard to health behaviors. ${ }^{20,21}$

Broad appeal across audiences. The psychology of familiarity may explain the broad appeal of game design language. Game experience is now so entrenched in our culture that games elements and game design become approachable and appeal to wider populations. ${ }^{17}$

Everyday life fit. Gamified systems are typically in line with already-ongoing everyday behaviors facilitating interventions efficacy.

Supporting well-being. Gamified interventions offer a wide range of possibilities for generating positive experiences of task accomplishment and social relationships, as well as other elements of well-being, like positive emotions. ${ }^{10}$

This study aimed to assess the impact of a web-based gamification program delivered through classrooms on nutrition literacy of families with children 3-5 years old and explore differences in impact by socioeconomic status.

\section{METHODS}

The Nutriscience Project is a prospective follow-up program implemented in 2016 that aimed to improve nutrition literacy in families of 3-5-yearold children after a web-based intervention using a gamified multiplatform strategy. The main topics addressed in this project were promotion of fruit and vegetable consumption and decreasing sugar and salt intake, according to the priorities of the World Health Organization. ${ }^{22}$ The evaluation study was performed during 3 months with intervention and control groups.

\section{Participants and Procedures}

A convenience nonrandom sample of 37 kindergartens (59 classrooms and 877 families) were invited to participate in the program; from those, 32 were allocated to the intervention group and 5 to the control group, targeting a minimum of 1 kindergarten from each administrative region of Portugal. All the families with 3-5year-old children were invited to participate in this project through the participating classrooms. From the invited families, $63 \%$ agreed to participate. However, only 106 families from the intervention group and 83 from the control group completed pre and post questionnaires. Explanations on how to participate in the project and access the platform were provided in 3 regional meetings with educators and school directors. In addition, an introductory video and a PowerPoint presentation (Microsoft Corporation, Redmond, WA) was given to educators to present at parent meetings, and a pamphlet was distributed to all the eligible parents through the classrooms. Families from both intervention and control groups completed a questionnaire assessing nutrition literacy at the beginning and at the end of the intervention period (3-month period). After the second assessment, families from the control group were invited to access the platform and all the contents.

\section{Intervention Model Design}

The model behind Nutriscience (Figure) is structured around 3 main interconnected strategies aimed at promoting nutrition literacy: (1) parents' level of intervention; (2) children's level of intervention; (3) educators' level of intervention. The children's level was based on contents like comics and a serious game app (TuttiNutriScience) promoting healthy food choices. The educators' level was based on a Massive Open Online Course on Nutrition (10 modules) and lasted for 5 weeks. Each module includes learning objectives, video, and activity sheets to be developed for children in the classroom. The Massive Open Online Course 


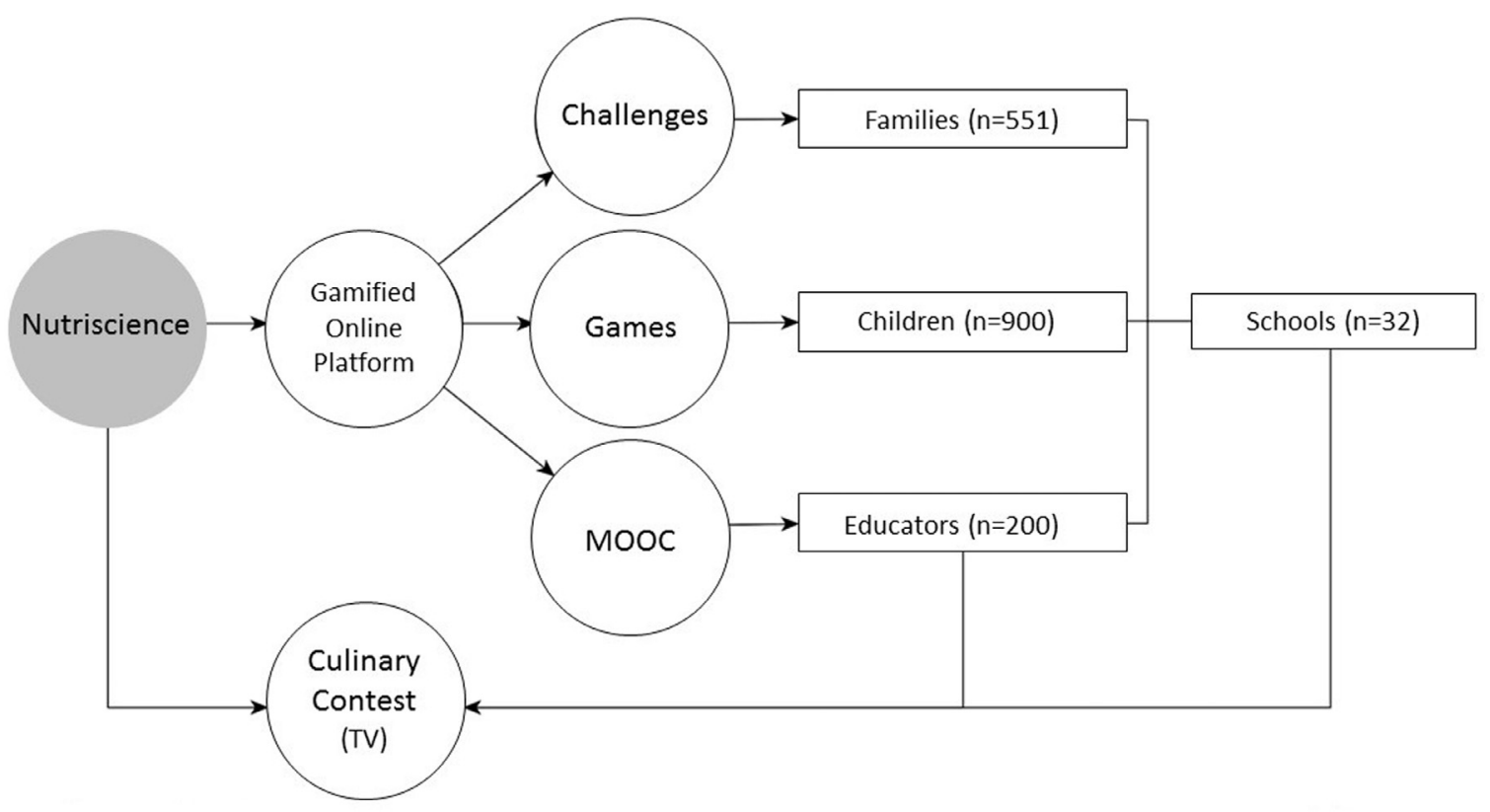

Baseline nutritional literacy assessment

Intervention

Final nutritional

literacy assessment

Figure. The Nutriscience intervention model: a web-based intervention using a gamified multiplatform strategy. MOOC indicates massive open online course.

was certified by the board of continuous training of teachers and educators (0.4 credits). This paper will focus on the parents' level of the intervention, which is described in more detail below.

The platform was developed as a social network environment where schools and families signed up for membership. Families accessed the interactive platform through a code, creating a "Family Page" with the name and photo (optional). The platform provides different layers of information: nutritional informative contents (videos, recipes, food "identity cards"), weekly challenges launched by the project team (related to the 3 intervention topics), news about events in the network, and an interactive space (forum and visualization/comments of other members' participation).

Weekly nutritional challenges (Table 1) were launched in the platform and were the main driver of interaction, encouraging family involvement in real life with a sharing online, for example, (a) recipes preparation (a vegetable soup with pulses and no added salt, a Mediterranean Diet main dish, low sugar dessert, etc); (b) analyzing food labeling (compare the amount of sugar in 2 different yogurts, find the amount of salt of a processed food); (c) foodrelated activities (planting aromatic herbs). The platform allowed the participants to visualize their performance through bar of completion and to get a badge for each of the 3 topics when all 3 challenges for that topic are completed. In each topic there was a challenge related to a recipe. Uploaded recipes received feedback on their nutritional quality and were ranked based on nutritional quality, creativity, and cultural relevance. In total, 30 recipes were chosen to be performed by a chef at a national TV channel and to be included in a cookbook based on the ranking and representativeness of regional diversity (north/south, coast/inland).

In classrooms, educators accessed the platform through an institutional code, and had 3 weekly nutritional challenges about healthy eating related to arts, music, and drama to complete in class with children and to share through the platform. All the participating classrooms also had access to educational contents available in the platform. The involvement of the classroom community (educators and other professionals) was considered fundamental, since the intervention had a holistic approach and the educators-families relation was essentially a motivational strategy for participation.

In addition, an open Facebook page for the Nutriscience Project was created in order to increase its visibility.

\section{Nutrition Literacy Assessment}

To assess changes in parents' nutrition literacy, a parental self-reported questionnaire was applied, which was filled out on the Nutriscience online platform. For the control group, a paper-based version of the questionnaire was handed out and returned through the classrooms.

The questionnaires were administered before and after the intervention, assessing (1) sociodemographic characteristics (respondent's age and degree of kinship; number of household members; household classification; number of household children; gender and age of participant child; educational level, job situation, and type of work institution of respondent and his/her spouse, and perceived income status), ${ }^{23}$ and (2) food and nutrition literacy.

Educational level was recoded into the following categories (more than 
Table 1. Nutriscience ${ }^{a}$ Families Intervention Challenges

\begin{tabular}{|c|c|c|c|c|}
\hline & Topic & Date & Challenge & Answer \\
\hline \multirow[t]{3}{*}{$\begin{array}{l}\text { October } 3 \text { to } \\
\text { October 23, } 2016\end{array}$} & \multirow[t]{3}{*}{$\begin{array}{l}\text { Fruit and } \\
\text { vegetables }\end{array}$} & $\begin{array}{c}\text { October } 3 \text { to } \\
\text { October } 9\end{array}$ & $\begin{array}{l}\text { Development and preparation } \\
\text { of a soup recipe with } \\
\text { legumes }\end{array}$ & $\begin{array}{l}\text { To submit the soup photo- } \\
\text { graph and its recipe }\end{array}$ \\
\hline & & $\begin{array}{l}\text { October } 10 \text { to } \\
\text { October } 16\end{array}$ & $\begin{array}{l}\text { Development and preparation } \\
\text { of a dessert only with fruit } \\
\text { (using seasonal fruit) }\end{array}$ & $\begin{array}{l}\text { To submit the dessert photo- } \\
\text { graph and its recipe }\end{array}$ \\
\hline & & $\begin{array}{l}\text { October } 17 \text { to } \\
\text { October } 23\end{array}$ & $\begin{array}{l}\text { Development and preparation } \\
\text { of a Mediterranean } \\
\text { recipe-main dish }\end{array}$ & $\begin{array}{l}\text { To submit the main dish pho- } \\
\text { tograph and its recipe }\end{array}$ \\
\hline \multirow[t]{3}{*}{$\begin{array}{l}\text { October } 24 \text { to } \\
\text { November 13, } 2016\end{array}$} & \multirow[t]{3}{*}{ Salt } & $\begin{array}{l}\text { October } 24 \text { to } \\
\text { October } 30\end{array}$ & $\begin{array}{l}\text { Creation a small herbs' plan- } \\
\text { tation in the kitchen }\end{array}$ & $\begin{array}{l}\text { To submit the herbs' planta- } \\
\text { tion photograph }\end{array}$ \\
\hline & & $\begin{array}{r}\text { October } 31 \text { to } \\
\text { November } 6\end{array}$ & $\begin{array}{l}\text { Development and preparation } \\
\text { of a traditional dish of fami- } \\
\text { lies' region with less salt }\end{array}$ & $\begin{array}{l}\text { To submit the dish photo- } \\
\text { graph and its recipe }\end{array}$ \\
\hline & & $\begin{array}{l}\text { November } 7 \text { to } \\
\text { November } 13\end{array}$ & $\begin{array}{l}\text { Find out how much salt there } \\
\text { is in food from its label } \\
\text { (choose } 2 \text { options): } \\
\text { 1) ham } \\
\text { 2) pizza } \\
\text { 3) culinary broth }\end{array}$ & $\begin{array}{l}\text { To submit a document or a } \\
\text { photograph with salt content } \\
\text { comparison between } \\
\text { products }\end{array}$ \\
\hline \multirow[t]{3}{*}{$\begin{array}{l}\text { November } 21 \text { to } \\
\text { December 13, } 2016\end{array}$} & \multirow[t]{3}{*}{ Sugar } & $\begin{array}{l}\text { November } 21 \text { to } \\
\text { November } 27\end{array}$ & $\begin{array}{l}\text { Preparation of a breakfast or a } \\
\text { lunchbox with low sugar } \\
\text { content }\end{array}$ & $\begin{array}{l}\text { To submit the photograph and } \\
\text { the description of the meal }\end{array}$ \\
\hline & & $\begin{array}{l}\text { November } 28 \text { to } \\
\text { December } 4\end{array}$ & $\begin{array}{l}\text { Compare } 2 \text { labels of one type } \\
\text { of product (choose one) } \\
\text { 1) } 2 \text { different types of cookies } \\
\text { 2) } 2 \text { different types of yogurts }\end{array}$ & $\begin{array}{l}\text { To submit a document or a } \\
\text { photograph with sugar con- } \\
\text { tent of the selected products }\end{array}$ \\
\hline & & $\begin{array}{l}\text { December } 5 \text { to } \\
\text { December } 13\end{array}$ & $\begin{array}{l}\text { Preparation of a traditional } \\
\text { Christmas dessert (chosen } \\
\text { by each family) }\end{array}$ & $\begin{array}{l}\text { To submit the dessert photo- } \\
\text { graph and its recipe }\end{array}$ \\
\hline
\end{tabular}

${ }^{a}$ Nutriscience is a gamification approach to improving nutrition literacy by challenging family participation.

12 years of schooling - 'high educational level'; 12 years of schooling or less - 'low educational level'. The Nutrition Literacy questionnaire was based on the Nutrition Literacy Assessment Instrument (NLAI), published by the Centers for Disease Control and Prevention. ${ }^{24}$ The NLAI has 5 different sections regarding nutrition and health, macronutrients, household food measurement, food labels and numeracy, and food groups. ${ }^{24,25}$

The Nutrition literacy questions were adapted to the Portuguese setting, regarding Portuguese food habits and the 3 major topics of the project (promoting the consumption of fruit and vegetables; reducing the intake of sugar and salt), resulting in 20 questions covering 4 different dimensions: Nutrients (6 items), Food Portions (3 items), Portuguese Food Wheel Guide Groups (7 items), and Food Labeling (4 items). Two important modifications were introduced to NLAI: disease-related questions were removed from the NLAI questionnaire, taking into account the objectives of the project, focusing on a health promotion approach rather than focusing on the relationship between diet and disease. Regarding food portions, the changes were culturally induced, they were adapted to the food recommendations in the Portuguese food guide. The objective was to assess the knowledge of participants regarding the adequate amount of food for a meal - portions - and the proportion between portions of vegetables, as well as protein and carbohydrate food sources in the plate of a main meal. Particular emphasis was given to the portion of vegetables in line with one of the central objectives of the project - the increase of its consumption.
Therefore, it was decided to include 3 examples of main meals in which vegetables are usually consumed according to Portuguese dietary habits, showing different proportions of the 3 main components of a Portuguese main meal (meat/fish, starchy food, and vegetables). A pretest was conducted in a sample of 10 families with 3-5-year-old children, to help refine the wording and layout of the questionnaire and evaluate the time taken to fill it out, and the eventual misunderstanding of the questions. Informed by the results of pretest, minor changes were made to improve the clarity of the questionnaire.

The nutrition literacy score was obtained through the proportion of right answers (number of right answers, divided by the total number of questions and multiplied by 100). The project was approved by the 
Ethics Committee of University of Porto and National Commission for Data Protection. Informed consent indicating agreement of the parents to participate in this study was also requested before inclusion.

\section{Statistical Analysis}

Descriptive statistics included mean (SD) and proportions. General linear models (GLM) with repeated-measures analysis were used to analyze change in the nutrition literacy score over the Nutriscience intervention and to test 3 hypotheses: (1) the main effects on repeated measures of between-subjects (grouping) factor A (in this case, education or income); (2) the main effects of within-subjects (conditions) factor B (in this case, the Nutriscience Project); (3) interaction effect between factors.

The repeated-measures GLM procedure is "conceptually an extension of the ubiquitous ANOVA." ${ }^{26}$ The biggest advantage of this method is its conceptual simplicity and the way it deals with possible clustering of data. "Earlier (first-generation) studies probably over-estimating school effects because they treated the school variable as one among several characteristics of individuals." ${ }^{27}$ A review indicates that "for the future, multilevel studies are the empirical approach of choice," since it takes account of the hierarchical structure of the data. ${ }^{28}$ In this study, the effects of school- and individual-level factors could be estimated simultaneously using the intraclass correlation coefficient (ICC) as a preliminary analysis to determine the most appropriate model-to-data agreement. The ICC assesses the degree of clustering or dependency among subsets of cases in nested data. When the ICC is close to 0 , as happened in this study, clustering is not present in the data and simple GLM is the most statistically appropriate procedure to implement. Otherwise, mixed models should be used.

\section{RESULTS}

Sociodemographic characteristics are described in Table 2 and did not differ significantly between the intervention and control groups (Table 2).
Indicators of Family Engagement With the Platform

During the Nutriscience Program, a total of 1267 uploads from families (including recipes and photographs of challenges) were recorded on the interactive platform. There was a total of 512 answers for 'fruit and vegetables' challenges (1st group of challenges), 412 to 'salt' challenges (2nd group of challenges), and 343 to 'sugar' challenges (3rd group of challenges) by the families. Considering the 3-week challenges for classrooms, 27 'Nutriscience mascots' (1st challenge), 25 'Nutriscience hymn/choreography' (2nd challenge), and 14 'Nutriscience children theatre's plays (3rd challenge) were developed.

\section{Impact of the Nutriscience Project on Nutrition Literacy}

For the intervention group, the final mean (SD) score was significantly higher than the baseline one: $78.8 \%$ (15.6) vs $72.7 \%$ (16.2); $(P<.001)$ (Table 3). The significant $P$-value for Nutriscience intervention shows an

Table 2. Sociodemographic Characteristics of the Participants ${ }^{a}$ (Intervention Group, $n=106 ;$ Control Group, $n=83$ )

$\begin{array}{lc}\text { Educational level (years) } & \\ <10 & 10(9.3) \\ 10-12 & 27(25.5) \\ >12 & 69(65.1) \\ \text { Income perception } & \\ \text { Live comfortable } & 18(17) \\ \text { Can live } & 66(62.3) \\ \text { Live with difficulties } & 22(20.8) \\ \text { Household classification } & \\ \text { Mother or father with children } & 7(6.6) \\ \text { Couple with children } & 93(87.7) \\ \text { Couple with children and other } & 6(5.7) \\ \text { Number of children } & \\ 1 & 55(51.9) \\ 2 & 44(41.5) \\ \geq 3 & 7(6.6) \\ \text { Job situation } & \\ \text { Employed/paid internship } & 94(88.7) \\ \text { Unemployed } & 5(4.7) \\ \text { Other } & 7(6.4)\end{array}$

\section{Control Group n (\%)}

8 (9.6)

$31(37.3)$

44 (53.0)

9 (10.8)

55 (66.3)

19 (22.9)

$6(7.2)$

$72(86.7)$

5 (6.0)

38 (46.3)

$39(47.6)$

5 (6.1)

$73(88.0)$

7 (8.4)

3 (3.6)
Significance Value

.194

.486

.979

.708

.406

\section{Median}

37
Minimum

19
Maximum

47

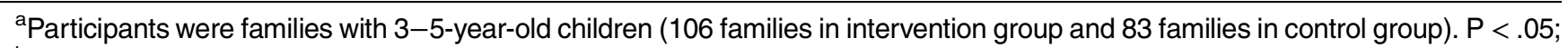

${ }^{\text {b}}$ Student, retired, disable, military/community work, domestic, another inactivity situation. 


\section{Table 3. Nutrition Literacy Over Time ${ }^{a}$ Using General Linear Models (GLM) With Repeated Measures}

Mean Score (SD) Baseline Mean Score (SD) Final Mean Difference Within-Subjects ( $P$-Value)

$\begin{array}{llllr}\text { Intervention group } & 72.7(16.2) \% & 78.8(15.6) \% & 6.1 & <.001 \\ \text { Control group } & 66.4(15.6) \% & 67.8(16.1) \% & 1.4 & .364\end{array}$

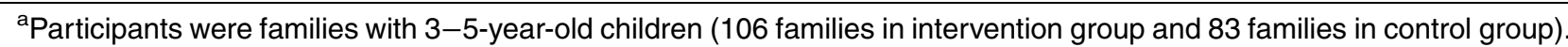
$P<.05$.

effect on the nutritional scores - a within-subjects effect reflected by the repeated measures. In the control group, no significant difference between the final and initial scores was observed [67.8\% (16.1) vs $66.4 \%$ (15.6)] $(P=.364)$ (Table 3$)$. It could also be possible that nutritional literacy scores are confounded by conditions such as income and education. Nevertheless, according to Table 4, there is a nonsignificant interaction between time and education $(P=.324)$, and between time and income $(P=.338)$. Therefore, Nutriscience intervention is the only statistically significant variable affecting literacy scores. Also worth noting is the between-subjects effects, which determine if respondents differ on scores, depending on their group. In this case, according to Table 4, nutritional scores are statistically different according to education level $(P=.003)$ and income $(P=.026)$. However, since this study was not powered, any nonsignificant results should be cautionary since a lack of significant results could be caused by too few participants.

\section{DISCUSSION}

The implementation of a gamified web-based intervention as an alternative to face-to-face approaches highlights a potentially fruitful line of research. The significant improvement of the nutrition literacy of the participant families regardless of parental education and perceived income status was particularly relevant. Previous studies have failed on engaging individuals from lower socioeconomic levels in this kind of intervention on healthy eating promotion. ${ }^{29,30}$ Despite advancements, questions remain mainly around the issues of assessing literacy and mechanisms of change.

First, little attention has been paid to establishing valid instruments for measuring nutrition literacy. ${ }^{31}$ Some of the available questionnaires were focused mainly on global health, ${ }^{32-37}$ and there were few related to nutrition literacy. ${ }^{25,38-40}$ The field landscape is therefore characterized by a certain confusion of concepts. Articles were found using terms like food literacy, nutrition literacy or functional literacy, interactive literacy, critical literacy (all applied to nutrition), and health literacy, apparently referring to similar issues. $^{25,32,41}$ Two food and nutrition literacy questionnaires validated for Portuguese population were found, ${ }^{42,43}$ but required a high baseline literacy by the target population. Those questionnaires were focused, respectively, on labels reading and calculation $^{38}$; and nutrition topics like antioxidants, micronutrients, and nutritional therapy for diseases $^{39}$; as the Nutriscience Project aimed to reach the whole spectrum of social socioeconomic status, these questionnaires were not appropriate. Second, an important point to discuss is the underlying mechanisms of change for intervention.
It is not possible to separate the effect of the various components of such a comprehensive ecological intervention. Providing the nutritional intervention to the whole educational community per se was certainly a key aspect of the success of the intervention. Nevertheless, a number of other dimensions (experiential learning; social norms through benchmarking against others and professionally set standards/recommendations; role modeling/vicarious learning) are likely to have contributed to improve nutrition literacy.

Nutrition literacy is not just about information, but also requires other skills related to what people actually do with the knowledge being communicated. Effective communication does not happen by pushing messages on to people. It only happens when the receivers understand and make meaning of those messages. ${ }^{44-47}$ Families were challenged to develop tasks and to train practical skills such as preparing a vegetable soup with pulses, cooking a traditional recipe with reduced salt content, and selecting healthy foods while purchasing or planting culinary herbs ("kitchen garden"). Experiential learning strategies have been considered the most effective to promote healthy eating. ${ }^{48}$ Therefore, the impact of involving the family in the preparation of healthy meals through active cooking is expected to be higher than other strategies such as passively transmitting knowledge from a purely theoretical point of view.

Table 4. Impact of Intervention Program in Nutrition Literacy in Families According to Education and Income Perception

Significance Value

\begin{tabular}{lcc} 
& & \\
\cline { 2 - 3 } & Between-Subjects & Interaction \\
Education level & .003 & .324 \\
Income perception & .026 & .338 \\
\hline
\end{tabular}

\footnotetext{
${ }^{\text {a }} P$ values calculated through general linear model for repeated measures.
} 
The gamification design allowed the diffusion of sustainable nutritional behavior within the community by activating perceived social norms. (The forum allowed participants to interact and share experiences. Participants could also see recipes from other families, comment, and add to their favorites). A large number of people do not know what to think about nutrition, with all the media mixed messages bombarding them. ${ }^{49}$ It is therefore important that choosing healthy meals is made visible so as to activate the desired norm. ${ }^{50}$ For instance, the introduction of a points system (often used in gamified applications) based on schools' participation displayed in a leader board and ranked schools against each other. Such a ranking is often used in gamified applications, thereby allowing people to compare their ranking against others. As Bandura ${ }^{51}$ points out, vicarious experiences provided by social models are one of the main sources that influence an individual's perceived self-efficacy. This means that a gamification strategy may involve peer modeling activating and increasing self-efficacy by raising beliefs of being capable of mastering activities.

This study has several limitations that should be pointed out. This study uses a nonrandom sampling method, and the sample size of the control group was small in comparison with the intervention group. An online questionnaire was used, which might reduce the response rate of certain demographic groups. The short duration time presents another limitation.

This intervention was focused on specific nutrition objectives, which led to a more accurate intervention. Secondly, parents were used as the main agents to be involved in this intervention. Further, this project was focused on enhancing motivation for participation and learning process. Finally, educators were also involved in this intervention to facilitate the environmental changes in schools.

It is demanding for health researchers to think about the different ways people acquire new behaviors so they can be successful at population-level changes with respect to nutrition literacy. ${ }^{52}$ Gamification could be a promising approach in helping to bridge the intention-behavior gap for a potentially large group of individuals.

\section{IMPLICATIONS FOR RESEARCH AND PRACTICE}

The Nutriscience Project provided families and classroom staff with significant information (booklets, online comments, and other written information) about what are considered the best practices for intervention in families and schools. Using a digital and entertaining interactive platform seems to be a useful, easily adapted and disseminated education tool for a healthy eating learning process. However, future implementations of the Nutriscience Project will benefit from a longer time intervention, at least 5 months duration, ${ }^{53}$ along with an assessment of the eating habits of families and school communities before and after the intervention period. Markers of the interaction with the platform, such as the time that participants are exposed, could also be further explored. Further research is needed to determine the effectiveness of gamification in the health and wellbeing domain. Particularly, more well-designed studies comparing gamified and nongamified interventions, gamification approaches with and without ecological designs, and other relevant comparisons with long-term follow-up assessments of outcomes are welcomed. In addition, in future research, social interaction phenomena, within the family, between families, and between families and schools, could be assessed, as well as their impact on participants' nutrition literacy.

\section{ACKNOWLEDGMENTS}

Funded by the EEA Grants Program (Project 0085NU1), with the support of the National Health Service (Ministry of Health), and the Central Administration of the Health System and Public Health Initiatives.

\section{REFERENCES}

1. GBD 2015 Mortality and Causes of Death Collaborators. Global, regional, and national life expectancy, all-cause mortality, and cause-specific mortality for 249 causes of death, 1980-2015: a systematic analysis for the Global Burden of Disease Study 2015. Lancet. 2016;388:1459-1544.

2. Alwan A, editor. Global Status Report on Noncommunicable Diseases, Geneva, Switzerland: World Health Organization; 2011.

3. Lopes C, Torres D, Oliveira A, et al. Inquérito Alimentar Nacional e de Atividade Física (IAN-AF 2015-2016). Porto, Portugal: University of Porto; 2017.

4. Institute for Health Metrics and Evaluation. Global Burden of Disease (GBD) Data Visualizations. http://www.healthmetricsandevaluation.org/gbd/visualizations/country. Accessed October 24, 2018.

5. Carbone ET, Zoellner JM. Nutrition and health literacy: a systematic review to inform nutrition research and practice. J Acad Nutr Diet. 2012;112: 254-265.

6. Natale R, Chang C, Messiah S. Obesity prevention in young children. In: Ahmad SI, Imam SK, eds. Obesity, London: Springer International Publishing; 2016:335-349.

7. McLeroy KR, Bibeau D, Steckler A, Glanz K. An ecological perspective on health promotion programs. Health Educ Q. 1988;15:351-377.

8. Stokols D. Translating social ecological theory into guidelines for community health promotion. Am J Health Promot. 1996;10:282-298.

9. Richard L, Gauvin L, Raine K. Ecological models revisited: their uses and evolution in health promotion over two decades. Annu Rev Public Health. 2011;32:307-326.

10. Johnson D, Deterding S, Kuhn K-A, Staneva A, Stoyanov S, Hides L. Gamification for health and wellbeing: a systematic review of the literature. Internet Interv. 2016;6:89-106

11. Seaborn K, Fels DI. Gamification in theory and action: a survey. Int J Hum Comput Stud. 2015;74:14-31.

12. Ershow AG, Peterson CM, Riley WT, Rizzo AS, Wansink B. Virtual reality technologies for research and education in obesity and diabetes: research needs and opportunities.J Diabetes Sci Technol. 2011;5:212-224. 
13. Maher CA, Lewis LK, Ferrar K, Marshall S, De Bourdeaudhuij I, Vandelanotte C. Are health behavior change interventions that use online social networks effective? A systematic review. J Med Internet Res. 2014;16:e40.

14. Laranjo L, Arguel A, Neves AL, et al. The influence of social networking sites on health behavior change: a systematic review and meta-analysis. J Am Med Inform Assoc. 2015;22: 243-256.

15. Bort-Roig J, Gilson ND, Puig-Ribera A, Contreras RS, Trost SG. Measuring and influencing physical activity with smartphone technology: a systematic review. Sports Med. 2014;44:671-686.

16. Deterding S. The lens of intrinsic skill atoms: a method for gameful design. Hum Comput Interact. 2015;30:294-335.

17. King D, Greaves F, Exeter C, Darzi A. 'Gamification': influencing health behaviours with games. $J$ R Soc Med. 2013;106:76-78.

18. Munson S, Poole E, Perry DB, Peyton T. Gamification and health. In: Walz SP, editor. The Gameful World Approaches, Issues, Applications. Cambridge, London: MIT Press; 2015:597-623.

19. Pereira P, Duarte E, Rebelo F, Noriega P. A review of gamification for healthrelated contexts. Paper presented at: Third International Conference on Design, User Experience, and Usability; June 22-27, 2014. Heraklion, Crete, Greece..

20. Ng JY, Ntoumanis N, ThogersenNtoumani C, et al. Self-determination theory applied to health contexts: a meta-analysis. Perspect Psychol Sci. 2012;7:325-340.

21. Patrick H, Williams GC. Self-determination theory: its application to health behavior and complementarity with motivational interviewing. Int $J$ Behav Nutr Phys Act. 2012;9:18.

22. World Health Organization (WHO). Fact Sheet $n^{\circ}$ 394: Healthy Diet. Geneva, Switzerland: WHO; 2015.

23. Mantziki K, Vassilopoulos A, Radulian $\mathrm{G}$, et al. Promoting health equity in European children: design and methodology of the prospective EPHE (Epode for the Promotion of Health Equity) evaluation study. BMC Public Health. 2014;14:303.

24. Gibbs H, Chapman-Novakofski K. Establishing content validity for the Nutrition Literacy Assessment Instrument. Prev Chronic Dis. 2013;10:E109.
25. Gibbs HD. Nutrition literacy: foundations and development of an instrument for assessment [dissertation]. Urbana, Illinois: University of Illinois at Urbana-Champaign. 2012. https://digitalcommons.olivet.edu/facs_facp/1.

Accessed October 24, 2018.

26. Hickey GL, Mokhles MM, Chambers DJ, Kolamunnage-Dona R. Statistical primer: performing repeated-measures analysis. Interact Cardiovasc Thorac Surg. 2018;26:539-544.

27. West P, Sweeting H, Leyland A. School effects on pupils' health behaviours: evidence in support of the health promoting school. Res Pap Educ. 2004;19: 261-291.

28. Aveyard P, Markham WA, Cheng KK. A methodological and substantive review of the evidence that schools cause pupils to smoke. Soc Sci Med. 2004;58:2253-2265.

29. Loring B, Robertson A. Obesity and Inequities. Guidance for Addressing Inequities in Overweight and Obesity. Copenhagen, Denmark: World Health Organization; 2014.

30. Oldroyd J, Burns C, Lucas P, Haikerwal A, Waters E. The effectiveness of nutrition interventions on dietary outcomes by relative social disadvantage: a systematic review. J Epidemiol Community Health. 2008;62:573-579.

31. Guttersrud O, Dalane JO, Pettersen S. Improving measurement in nutrition literacy research using Rasch modelling: examining construct validity of stagespecific 'critical nutrition literacy' scales. Public Health Nutr. 2014;17:877-883.

32. Davis TC, Long SW, Jackson RH, et al. Rapid estimate of adult literacy in medicine: a shortened screening instrument. Fam Med. 1993;25:391-395.

33. Parker RM, Baker DW, Williams MV, Nurss JR. The test of functional health literacy in adults: a new instrument for measuring patients' literacy skills. J Gen Intern Med. 1995;10:537-541.

34. Lee SY, Stucky BD, Lee JY, Rozier RG, Bender DE. Short Assessment of Health Literacy-Spanish and English: a comparable test of health literacy for Spanish and English speakers. Health Serv Res. 2010;45:1105-1120.

35. Sorensen K, Van den Broucke S, Pelikan JM, et al. Measuring health literacy in populations: illuminating the design and development process of the European Health Literacy Survey Questionnaire (HLS-EU-Q). BMC Public Health. 2013;13:948.
36. Champlin S, Mackert M. Creating a screening measure of health literacy for the Health Information National Trends Survey. Am J Health Promot. 2016;30:291-293.

37. Jordan JE, Buchbinder R, Briggs AM, et al. The health literacy management scale (HeLMS): a measure of an individual's capacity to seek, understand and use health information within the healthcare setting. Patient Educ Couns. 2013;91:228-235.

38. Rowlands G, Khazaezadeh N, OtengNtim E, Seed P, Barr S, Weiss BD. Development and validation of a measure of health literacy in the UK: the newest vital sign. BMC Public Health. 2013;13:116.

39. Parmenter K, Wardle J. Development of a general nutrition knowledge questionnaire for adults. Eur J Clin Nutr. 1999;53:298-308.

40. Diamond JJ. Development of a reliable and construct valid measure of nutritional literacy in adults. Nutr J. 2007;6:5.

41. Krause C, Sommerhalder K, BeerBorst S, Abel T. Just a subtle difference? Findings from a systematic review on definitions of nutrition literacy and food literacy. Health Promot Int. 2018;33:378-389.

42. Souza JAd. Conhecimentos Nutricionais Reprodução e Validação do Questionário. Porto, Portugal: Faculdade de Medicina e Instituto de Ciências Biomédicas Abel Salazar, Universidade do Porto; 2009.

43. Martins A, Andrade I. Cross-cultural adaptation and validation of the portuguese version of the Newest Vital Sign. Revista Enfermagem Referencia. 2014; Série IV:75-83.

44. Velardo S. The nuances of health literacy, nutrition literacy, and food literacy. J Nutr Educ Behav. 2015;47: 385-389.

45. Cullen T, Hatch J, Martin W, Higgins JW, Sheppard R. Food literacy: definition and framework for action. Can J Diet Pract Res. 2015;76:140145.

46. Truman E, Lane D, Elliott C. Defining food literacy: a scoping review. Appetite. 2017;116:365-371.

47. Azevedo Perry E, Thomas H, Samra $\mathrm{HR}$, et al. Identifying attributes of food literacy: a scoping review. Public Health Nutr. 2017;20:2406-2415.

48. Dudley DA, Cotton WG, Peralta LR. Teaching approaches and strategies that promote healthy eating in primary 
school children: a systematic review and meta-analysis. Int J Behav Nutr Phys Act. 2015;12:28.

49. Nagler RH. Adverse outcomes associated with media exposure to contradictory nutrition messages. $J$ Health Commun. 2014;19:24-40.

50. Higgs S, Thomas J. Social influences on eating. Curr Opin Behav Sci. 2016;9:1-6.
51. Bandura A. Self-Efficacy: The Exercise of Control. New York: W. H. Freeman; 1997.

52. Pray L. Food Forum, Food and Nutrition Board, Institute of Medicine, National Academies of Sciences - Engineering and Medicine. Food Literacy: How Do Communications and Marketing Impact Consumer Knowledge, Skills, and
Behavior?: Workshop Summary. Washington, DC: The National Academies Press; 2015.

53. Murimi MW, Kanyi M, Mupfudze T, Amin MR, Mbogori T, Aldubayan K. Factors influencing efficacy of nutrition education interventions: a systematic review. J Nutr Educ Behav. 2017;49: 142-165.

\section{Help JNEB Promote Your Article Via Social Media}

JNEB promotes its authors and articles on social media with each issue published. Be sure to provide a social media question and up to 5 social media accounts to help us find you and to promote your research on social media. 